\title{
Digestibility and Bioavailability of the Active Components of Erica australis L. Aqueous Extracts and Their Therapeutic Potential as Acetylcholinesterase Inhibitors
}

\author{
Pilar Dias, ${ }^{1}$ Pedro L. Falé, ${ }^{1,2}$ Alice Martins, ${ }^{1}$ and Amélia P. Rauter ${ }^{1}$ \\ ${ }^{1}$ Centro de Química e Bioquímica, Departamento de Química e Bioquímica, Faculdade de Ciências, Universidade de Lisboa, \\ Edifício C8, Campo Grande, 1749-016 Lisboa, Portugal \\ ${ }^{2}$ Institute of Pharmaceutical Science, King's College London, 150 Stamford Street, London SE1 9NH, UK
}

Correspondence should be addressed to Pedro L. Falé; pedro.vieira_fale@kcl.ac.uk and Alice Martins; aimartins@fc.ul.pt

Received 30 April 2015; Revised 14 July 2015; Accepted 15 July 2015

Academic Editor: Nunziatina De Tommasi

Copyright (c) 2015 Pilar Dias et al. This is an open access article distributed under the Creative Commons Attribution License, which permits unrestricted use, distribution, and reproduction in any medium, provided the original work is properly cited.

\begin{abstract}
Erica australis L. (Ericaceae) is used in traditional medicine to treat many free-radical related ailments. In the present work, the stability and biological activity of the plant aqueous extracts submitted to an in vitro digestive process were investigated. Chemical stability was monitored by HPLC-DAD and LC-MS/MS, while the bioactivities were evaluated through the inhibition of acetylcholinesterase (AChE) and DPPH radical scavenging activity. Both extracts, whose main components were flavonol glycosides, inhibited AChE, showing $\mathrm{IC}_{50}$ values of $257.9 \pm 6.2 \mu \mathrm{g} / \mathrm{mL}$ and $296.8 \pm 8.8 \mu \mathrm{g} / \mathrm{mL}$ for the decoction and for the infusion, respectively. Significant radical scavenging activities were also revealed by both extracts, as denoted by the $\mathrm{IC}_{50}$ values for the decoction, $6.7 \pm 0.1 \mu \mathrm{g} / \mathrm{mL}$, and for the infusion, $10.5 \pm 0.3 \mu \mathrm{g} / \mathrm{mL}$. After submission to gastric and pancreatic juices, no remarkable alterations in the composition or in the bioactivities were observed, suggesting that the extracts may pass through the gastrointestinal tract, keeping their composition and therefore their biological properties. Moreover, the bioavailability of the components of both extracts, as studied in a Caco-2 cell model, showed that compounds can permeate the membrane, which is a condition to exert their biological activities. Our results add further support to the potential of E. australis for its antioxidant and neuroprotective properties.
\end{abstract}

\section{Introduction}

Erica species (Ericaceae) are used in folk medicine of many countries for their therapeutic properties such as antiviral [1], diuretic [2], anti-inflammatory and antinociceptive [3], antioxidant $[4,5]$, antiulcer [6,7], antimicrobial [8], hypolipidaemic [9], analgesic [10], and cytotoxic [11] activities.

The flowers and aerial parts of Erica australis L. are used in the Trás-os-Montes region (Portugal) to treat prostate, bladder, and kidneys diseases [12] while, in the Montemuro mountains, the plant infusion is claimed to have anti-inflammatory, diuretic, and sedative properties. Studies involving E. australis collected in Algarve were recently reported [13-15]. These authors determined the antioxidant and free-radical scavenging activities of different plant parts of Erica australis L. and the phenolic, flavonoid, and amino acid profiles of the leaves and flowers from this plant. In addition, the effects of the plant extracts on Caco-2 cells, fibroblasts, and selected pathogenic bacteria responsible for wound infection were also investigated, showing the potential of this plant as a source of bioactive ingredients that may provide a diversity of health benefits. These properties can be attributed to its chemical constituents, mainly phenolic acids, flavonoids, amino acids, and anthocyanins [14, 16-20].

The present work is focused on E. australis collected in the Montemuro region, Portugal, concerning the digestibility and bioavailability of the active components of the plant aqueous extracts and their therapeutic potential as acetylcholinesterase (AChE) inhibitors.

The stability of extracts under gastrointestinal conditions was evaluated by HPLC-DAD-MS/MS before and after the submission to an in vitro digestion with artificial gastric 
and pancreatic juices. Furthermore, the antioxidant and antiacetylcholinesterase activities were monitored throughout the digestive process by the measurement of the DPPH radical scavenger activity and AChE inhibition. The bioavailability of E. australis extracts was also evaluated by the permeation of its components through Caco- 2 cell monolayers, a model of the intestinal barrier. As to our knowledge, this is the first report on the digestibility and bioavailability of the active compounds from $E$. australis aqueous extracts.

\section{Materials and Methods}

2.1. Plant Material. Samples of the flowering aerial parts of Erica australis were collected from wild populations in the Tarouca region, Montemuro mountain border. The plant was identified by Professor Ana Isabel Vasconcelos Correia, from the Herbarium of Jardim Botânico, Faculdade de Ciências da Universidade de Lisboa, where a voucher specimen (LISU 236833 ) is deposited. The infusion was obtained from flowering aerial parts collected by Ervital-Medicinal and Aromatic Plants, Ltd. (Castro Daire, Portugal).

2.2. Chemicals. All chemicals were of analytical grade. Acetylcholinesterase (AChE), acetylthiocholine iodide (AChI), 5,5-dithiobis(2-nitrobenzoic acid) (DTNB), and 2,2diphenyl-1-picrylhydrazyl (DPPH), pepsin, and pancreatin were obtained from Sigma (Barcelona, Spain). DMEM (Dulbecco's Modified Eagle's Medium), HBSS (Hank's Balanced Salt Solution) with and without phenol red, glutamine, Pen-Strep (penicillin and streptomycin mixture), PBS (phosphate buffered saline), and FBS (foetal bovine serum) were bought from Lonza (Verviers, Belgium). HPLC grade water, methanol, and trifluoroacetic acid were obtained from Merck (Darmstadt, Germany).

2.3. Extracts Preparation. Plant flowering aerial parts, previously dried at room temperature and away from direct sunlight, were used to prepare the decoction and the infusion (50 g plant/L boiling water). Then, both aqueous extracts were filtered through a Whatman number 1 paper, frozen, and lyophilized in a Heto PowerDry 3000 apparatus.

2.4. HPLC-DAD and LC-MS ${ }^{n}$ Analysis. The HPLC analysis was carried out in an Elite LaChrom VWR Hitachi Liquid Chromatograph equipped with a Column Oven L-2300 and Diode Array Detector L-2455 (VWR, USA). A column LiChroCART 250-4 LiChrospher 100 RP-8 (5 $\mu \mathrm{m})$ was used. The extract was analysed by HPLC, injecting $25 \mu \mathrm{L}(1 \mathrm{mg} / \mathrm{mL})$ with an autoinjector and using a gradient composed of solution A ( $0.05 \%$ trifluoroacetic acid) and solution B (methanol) as follows: $0 \mathrm{~min}, 80 \% \mathrm{~A}, 20 \% \mathrm{~B} ; 20 \mathrm{~min} 20 \% \mathrm{~A}, 80 \% \mathrm{~B}$; $25 \mathrm{~min}, 20 \% \mathrm{~A}, 80 \% \mathrm{~B}$. The flow rate was $1 \mathrm{~mL} / \mathrm{min}$ and the detection was carried out between 200 and $500 \mathrm{~nm}$ with a diode array detector.

The LC-MS and LC-MS ${ }^{n}$ analyses were carried out on a liquid chromatograph Surveyor Plus Modular LC system connected to a LCQ Duo ion trap mass spectrometer equipped with an electrospray ionization (ESI) source, from Thermo Scientific (Bremen, Germany). The column used was a LiChroCART 250-4 LiChrospher 100 RP-8 (5 $\mu \mathrm{m})$ column (Merck, Darmstadt, Germany). The extract was analyzed by the injection of the sample $(25 \mu \mathrm{L}, 1 \mathrm{mg} / \mathrm{mL})$ using a linear gradient composed of solution A (1.0\% formic acid) and solution $\mathrm{B}$ (methanol) as follows: $0 \mathrm{~min}, 70 \% \mathrm{~A}, 30 \% \mathrm{~B}$; $20 \mathrm{~min} 20 \% \mathrm{~A}, 80 \% \mathrm{~B} ; 25 \mathrm{~min}, 20 \% \mathrm{~A}, 80 \% \mathrm{~B}$. The mass spectrometer was operated in both positive and negative ion modes in the range $m / z 120-1000$ and the parameters were adjusted in order to optimize the signal-to-noise ratios $(\mathrm{S} / \mathrm{N})$ for the ions of interest. Briefly, the nebulizing and auxiliary gas (nitrogen) flow rates were 40 and 20 (arbitrary units) and the capillary temperature was set to $250^{\circ} \mathrm{C}$. Collision induced dissociation (CID) experiments were performed by isolating the ions within the ion trap and accelerating them in order to suffer multiple collisions with the background gas present in the ion trap (helium) using a data dependent acquisition mode. The ions of interest were activated by applying a percentage of a supplementary a.c. potential in the range of 0.75-1.75 Vp-p (peak-to-peak) to the end cap electrodes of the ion trap at the resonance frequency of the selected ion (referred to as the Normalized Collision Energy, NCE). The injection times were $50 \mathrm{~ms}$ in a full scan and $200 \mathrm{~ms}$ in a MS/MS scan. Xcalibur software from Thermo Scientific was used to acquire and process the data.

2.5. Antioxidant Activity. Antioxidant activity was measured by the DPPH method, as described in [21] with a slight modification. To a solution of DPPH (1.0 mL, $2 \%$ in methanol), $10 \mu \mathrm{L}$ of plant extract $(0-1.0 \mathrm{mg} / \mathrm{mL})$ was added. The mixture was incubated for $30 \mathrm{~min}$ at room temperature. The absorbance was measured at $517 \mathrm{~nm}$ against a corresponding blank. The antioxidant activity was calculated as

$$
\mathrm{AA}(\%)=100 \times \frac{\left(A_{\mathrm{DPPH}}-A_{\text {sample }}\right)}{A_{\mathrm{DPPH}}},
$$

where AA is the antioxidant activity, $A_{\mathrm{DPPH}}$ is the absorption of the DPPH solution against the blank, and $A_{\text {sample }}$ is the absorption of the sample against the blank. The tests were carried out in triplicate and the extract concentration providing $50 \%$ of antioxidant activity $\left(\mathrm{IC}_{50}\right)$ was obtained by plotting the antioxidant activity against the plant extract concentration.

2.6. Acetylcholinesterase Inhibition. Acetylcholinesterase enzymatic activity was measured using an adaptation of the method described by Ingkaninan and coworkers [22]. Briefly, Tris buffer $(325 \mu \mathrm{L} ; 50 \mathrm{mM}$; pH 8), sample solution $(100 \mu \mathrm{L})$, and acetylcholinesterase solution $(25 \mu \mathrm{L})$ containing $0.26 \mathrm{U} / \mathrm{mL}$ were mixed in a spectrophotometer cuvette and left to incubate for $15 \mathrm{~min}$ at $25^{\circ} \mathrm{C}$. Subsequently, solutions of AChI $(75 \mu \mathrm{L}, 0.023 \mathrm{mg} / \mathrm{mL})$ and DTNB $(475 \mu \mathrm{L}, 3 \mathrm{mM})$ were added. The absorbance at $405 \mathrm{~nm}$ was read during the first $5 \mathrm{~min}$ of the reaction and the initial velocity was calculated. A control reaction was carried out using water, which was considered to have $100 \%$ activity

$$
I(\%)=100-\left(\frac{V_{\text {sample }}}{V_{\text {control }}}\right) \times 100,
$$


where $I$ is the percent inhibition of acetylcholinesterase, $V_{\text {sample }}$ is the initial velocity of the extract containing reaction, and $V_{\text {control }}$ is the initial velocity of the control reaction. Tests were carried out in triplicate and a blank with buffer instead of enzyme solution was used. Results are expressed as the mean \pm standard deviation.

2.7. In Vitro Metabolism by the Gastric and Pancreatic Juices. The assay was adapted from [23]. Gastric or pancreatic juices $(1.25 \mathrm{~mL})$ were added to extract solution $(1.25 \mathrm{~mL}$, $3 \mathrm{mg} / \mathrm{mL}$ ) and the mixture was left to incubate at $37^{\circ} \mathrm{C}$ for $4 \mathrm{~h}$. Samples $(400 \mu \mathrm{L})$ were taken hourly, added to methanol $(400 \mu \mathrm{L})$, and centrifuged for $5 \mathrm{~min}$ at $5000 \times \mathrm{g}$. The supernatant was analysed by HPLC and used for the determination of acetylcholinesterase inhibition activity, as well as antioxidant activity, according to the procedures described previously. The gastric juice $(100 \mathrm{~mL})$ consisted of pepsin $(320 \mathrm{mg}), \mathrm{NaCl}(200 \mathrm{mg})$ acidified with $\mathrm{HCl}$ to $\mathrm{pH}$ 1.2. The pancreatic juice consisted of pancreatin $(250 \mathrm{mg})$ in potassium-phosphate buffer (10 mL; $50 \mathrm{mM}$; pH 8). All assays were done in triplicate.

2.8. Bioavailability Studies by Permeation through Caco2 Cell Monolayers. Bioavailability studies were performed according to the methodology described previously [24]. For transport and metabolism experiments, the cells were seeded at a density of $2-4 \times 10^{4}$ cells $/ \mathrm{cm}^{2}$ in 12 -well Transwell plate inserts with $10.5 \mathrm{~mm}$ diameter and $0.4 \mu \mathrm{m}$ pore size (BD Falcon). The monolayers were formed after 21-26 days. The integrity of the monolayers was evaluated by measuring the permeability of phenol red and the transepithelial electrical resistance (TEER) with a Millicell ERS-2 Volt-Ohm Meter, from Millipore (Darmstadt, Germany). The membranes were considered fit when the permeability of phenol red from apical to basolateral sides was less than $1 \%$ in one hour, or the TEER was higher than $250 \Omega \cdot \mathrm{cm}^{2}$. In general, to start the assays, the cells were washed with HBSS and $0.5 \mathrm{~mL}$ of the solutions to be tested, in HBSS, was applied into the Transwell inserts (apical side of the cells). The apical solution is composed of $0.5 \mathrm{mg} / \mathrm{mL}$ of extract in HBSS. Then, $1.5 \mathrm{~mL}$ of HBSS was added to the plate well (basolateral side of the cells).

After 6 hours of incubation at $37^{\circ} \mathrm{C}, 5 \% \mathrm{CO}_{2}$, the solutions in both sides of the cells were collected and analysed by HPLC. The cells were washed with HBSS and then scrapped and resuspended in HBSS. The cells were sonicated $5 \times 10 \mathrm{~s}$ and centrifuged $10 \mathrm{~min}$ at $5000 \times \mathrm{g}$, and the supernatant was analysed by HPLC. The concentration of E. australis extract used in the bioavailability assays was $1 \mathrm{mg} / \mathrm{mL}$, in HBSS, which was chosen because it did not show toxicity and did not affect the Caco-2 cell membrane integrity.

The percentage of permeation (\%) was calculated as the proportion of the original amount that permeated through the monolayer, which was calculated as the amount transported (mol) divided by the initial amount in the apical chamber (mol) [25]. The percentage of compound found inside the cells was also calculated by dividing the amount found in the cell lysate (mol) by the initial amount in the apical chamber (mol). When these amounts could not be

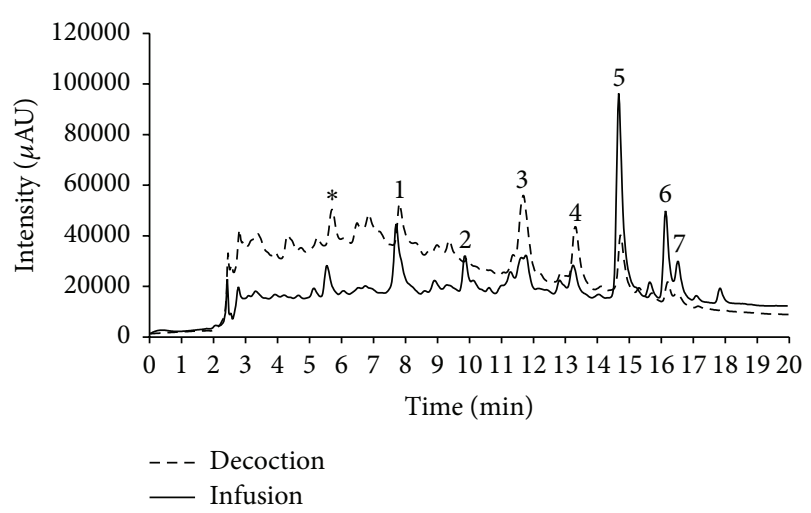

FIgURE 1: HPLC-DAD chromatogram (200-500 nm) of Erica australis aqueous extracts: unknown (1), gossypetin glycoside (2), myricetin 3-O-glucoside (3), myricetin 3-O-rhamnoside (4), quercetin 3-O-rhamnoside (5), kaempferol 3-O-rhamnoside (6), and quercetin acetylrhamnoside (7). ${ }^{*}$ The peak at $5.33 \mathrm{~min}$ is the result of an overlap of two smaller peaks. These two minority compounds were in amounts below the detection limit of the MS ${ }^{n}$ analysis and therefore could not be identified.

calculated in mole by the lack of standard compounds, the proportions were calculated based on the HPLC peak area and volume of solution. For convenience in comparing the values of infusion and decoction, the permeation rate of each compound was also estimated in the equivalent of $\mathrm{mol} / \mathrm{min}$ using the Lambert-Beer law and was calculated as

$$
\text { Permeation Rate }=\frac{\text { Amount }}{(\Delta t \cdot A)}=\frac{(\text { Peak Area } \cdot V)}{(\Delta t \cdot A)},
$$

where permeation rate is expressed in $\mathrm{mAU} \cdot \mathrm{mL}$, time $(t)$ in minutes, peak area in $\mathrm{mAU} \cdot \mathrm{min}$, volume $(V)$ in $\mathrm{mL}$, and membrane area $(A)$ in $\mathrm{cm}^{2}$.

2.9. Statistical Analysis. The software used was Microsoft Excel 2010 and the results were expressed as means \pm standard deviation. Additional analysis of variance (ANOVA) was performed, and a significant difference was assumed at a level of $P<0.05$.

\section{Results and Discussion}

3.1. Composition of Erica australis Aqueous Extracts. The phytochemical profile of $E$. australis aqueous extracts was evaluated by HPLC-DAD and LC-ESI-MS/MS and chromatograms of both extracts are depicted in Figure 1.

For each peak, the retention times, $\mathrm{UV}_{\max }$ values, and MS data are summarized in Table 1.

By comparing UV spectra and MS fragmentation patterns with literature data, seven glycosylated flavonols were tentatively identified in both extracts as gossypetin glycoside (2) [26], myricetin 3-O-glucoside (3) [27, 28], myricetin 3-Orhamnoside (4) [29], quercetin 3-O-rhamnoside (5) [30, 31], kaempferol 3-O-rhamnoside (6) [32], and quercetin acetylrhamnoside (7) $[33,34]$. However, unambiguous structural elucidation of these compounds will require their isolation 
TABLE 1: Putative identification of compounds present in Erica australis aqueous extracts, by HPLC-DAD and HPLC-ESI-MS ${ }^{n}$.

\begin{tabular}{|c|c|c|c|c|c|}
\hline Peak & $t_{R}(\min )$. & $\lambda_{\max }(\mathrm{nm})$ & Observed mass $[\mathrm{M}-\mathrm{H}]^{-}$ & $\begin{array}{c}m / z \text { product ions ESI-MS } \\
(\text { relative abundance, } \%)\end{array}$ & Compound \\
\hline 1 & 7.95 & - & - & - & Unknown \\
\hline 2 & 9.77 & $248,275,331$ & 479 & $\begin{array}{c}{\left[\mathrm{MS}^{2} 479\right]: 317(100) ;\left[\mathrm{MS}^{3} 317\right]: 299} \\
(100), 287 \text { (19), } 271(47), 255 \text { (12), } 231 \\
\text { (11) } 195(24)\end{array}$ & Gossypetin-glycoside \\
\hline 3 & 11.65 & $256,268,352$ & 479 & $\begin{array}{c}{\left[\mathrm{MS}^{2} 479\right]: 317(48), 316(100) ;\left[\mathrm{MS}^{3}\right.} \\
316]: 317 \text { (100), } 316(64), 287(15), 271 \\
(44)\end{array}$ & Myricetin 3-O-glucoside \\
\hline 4 & 13.28 & $258,271 \mathrm{sh}, 351$ & 463 & $\begin{array}{c}\left.\mathrm{MS}^{2} 463\right]: 317(30), 316(100) ;\left[\mathrm{MS}^{3}\right. \\
316]: 317 \text { (100), } 316(99), 287(19), 271 \\
(68)\end{array}$ & Myricetin 3-O-rhamnoside \\
\hline 5 & 14.69 & 256,269 sh, 348 & 447 & $\begin{array}{c}{\left[\mathrm{MS}^{2} 447\right]: 301(100), 300(35) ;\left[\mathrm{MS}^{3}\right.} \\
301]: 301(100), 271(34), 255(23), 179 \\
(62), 151(35)\end{array}$ & Quercetin 3-O-rhamnoside \\
\hline 6 & 16.11 & 269,348 & 431 & $\begin{array}{c}{\left[\mathrm{MS}^{2} 431\right]: 285(100), 284(35) ;\left[\mathrm{MS}^{3}\right.} \\
285]: 285(100), 257(16), 255(9), 229 \\
(7)\end{array}$ & Kaempferol 3-O-rhamnoside \\
\hline 7 & 16.24 & $257,269 \mathrm{sh}, 347$ & 489 & $\begin{array}{c}{\left[\mathrm{MS}^{2} 489\right]: 301(12), 300(100) ;\left[\mathrm{MS}^{3}\right.} \\
300]: 300 \text { (100), } 271(25), 255(46), 243 \\
(15), 201(11)\end{array}$ & Quercetin-acetylrhamnoside \\
\hline
\end{tabular}

sh: shoulder.

from both plant extracts. Compounds 3 and $\mathbf{4}$ were the major constituents of the decoction, while compounds 5 and $\mathbf{6}$ were present in major amounts in the infusion. Some of these glycosides as well as their aglycones (gossypetin, myricetin, kaempferol, and quercetin) were previously identified in other Erica species [16, 18-20, 35, 36].

\subsection{In Vitro Antioxidant and Antiacetylcholinesterase Activ-} ities. The radical DPPH is widely used to investigate the scavenging activities of several natural compounds or crude mixtures from plants [37]. E. australis aqueous extracts were proved to have a significant radical scavenging activity as demonstrated by the $\mathrm{IC}_{50}$ values for the decoction, $6.7 \pm$ $0.1 \mu \mathrm{g} / \mathrm{mL}$, and for the infusion, $10.5 \pm 0.3 \mu \mathrm{g} / \mathrm{mL}$. These results are within the range of the $\mathrm{IC}_{50}$ values from 296.3 to $4.9 \mu \mathrm{g} / \mathrm{mL}$ found for the leaves, flowers, and branches of $E$. australis evaluated separately, as reported previously by other authors [13].

The inhibition of AChE by both extracts was also evaluated and similar $\mathrm{IC}_{50}$ values were obtained for the decoction $(257.9 \pm 6.2 \mu \mathrm{g} / \mathrm{mL})$ and for the infusion $(296.8 \pm 8.8 \mu \mathrm{g} / \mathrm{mL})$. Extracts of several medicinal plants have been reported to be effective in the inhibition of BuChE and AChE [38], two enzymes involved in Alzheimer's disease. One of the most promising approaches for treating this disease is to enhance the acetylcholine level in the brain using AChE inhibitors [22]. AChE activity is also related to intestinal motility and AChE inhibitors are administered to treat dysphagia, gastric stasis achalasia, abdominal pain, paralytic ileus, vomiting, and constipation [39]. Several plants belonging to the Ericaceae family have shown a very strong activity against AChE and $\mathrm{BuChE} \mathrm{[38];} \mathrm{however,} \mathrm{to} \mathrm{our} \mathrm{knowledge,} \mathrm{no} \mathrm{previous}$ studies had been reported for the infusions or decoctions of Erica species. The $\mathrm{IC}_{50}$ values shown by $E$. australis extracts are lower than the ones found in the literature for many aqueous extracts of plants, such as Peumus boldus [40] and Hypericum sp. [41], as well as several species used as Portuguese food spices [42], which showed $\mathrm{IC}_{50}$ values between 350 and $1,240 \mu \mathrm{g} / \mathrm{mL}$. The strong inhibitory activity of E. australis aqueous extracts may be attributed to the presence of flavonols, mainly quercetin derivatives, which are reported to inhibit AChE enzyme [43].

3.3. In Vitro Gastrointestinal Digestion. In order to evaluate if the extracts could reach the intestinal tract without any modification in the chemical composition, the decoction and the infusion were subjected to the action of the gastric and pancreatic juices. Extracts were analysed by HPLCDAD, and by HPLC-ESI-MS/MS during $4 \mathrm{~h}$ and the chromatograms allowed the establishment of the graph shown in Figure 1. No remarkable modifications (data not shown) on the chemical composition of both extracts were observed, which is in accordance with the bioactivity results. There is some controversy about the stability of phenolic compounds submitted to in vitro digestions [44]. However, the use of different evaluation methodologies and the composition of food matrix can exert a strong influence on the behaviour of metabolites submitted to in vitro and in vivo digestive processes.

The antioxidant and anticholinesterase activities of $E$. australis extracts were analysed during the $4 \mathrm{~h}$ of the in vitro gastric and pancreatic process and results are shown in Table 2.

It can be seen that, after the gastric and pancreatic digestions, the AChE inhibition capacity and the antioxidant activity of the extracts showed small differences that are not 
TABLE 2: Antiacetylcholinesterase and antioxidant activities of Erica australis aqueous extracts before and after in vitro gastrointestinal digestion.

\begin{tabular}{|c|c|c|c|c|c|c|c|c|}
\hline \multirow{3}{*}{ Time (h) } & \multicolumn{4}{|c|}{$\operatorname{AChE}(\%)$} & \multicolumn{4}{|c|}{ DPPH (\%) } \\
\hline & \multicolumn{2}{|c|}{ Infusion } & \multicolumn{2}{|c|}{ Decoction } & \multicolumn{2}{|c|}{ Infusion } & \multicolumn{2}{|c|}{ Decoction } \\
\hline & Gastric & Pancreatic & Gastric & Pancreatic & Gastric & Pancreatic & Gastric & Pancreatic \\
\hline 0 & $100.0 \pm 27.5$ & $100.0 \pm 7.0$ & $100.0 \pm 7.6$ & $100.0 \pm 5.9$ & $100.0 \pm 18.9$ & $100.0 \pm 6.9$ & $100.0 \pm 5.6$ & $100.0 \pm 4.3$ \\
\hline 1 & $103.1 \pm 16.2$ & $94.0 \pm 6.8$ & $98.7 \pm 7.8$ & $98.0 \pm 3.7$ & $104.5 \pm 10.9$ & $101.6 \pm 4.3$ & $108.3 \pm 3.3$ & $102.4 \pm 13.1$ \\
\hline 2 & $123.5 \pm 18.0$ & $93.2 \pm 8.0$ & $97.7 \pm 3.7$ & $92.8 \pm 1.3$ & $103.3 \pm 4.7$ & $98.9 \pm 9.7$ & $110.9 \pm 8.7$ & $90.2 \pm 8.5$ \\
\hline 3 & $106.3 \pm 16.7$ & $98.2 \pm 8.6$ & $104.8 \pm 12.8$ & $95.0 \pm 10.7$ & $97.6 \pm 9.0$ & $100.1 \pm 8.6$ & $109.7 \pm 17.2$ & $92.7 \pm 8.4$ \\
\hline 4 & $105.2 \pm 10.8$ & $104.1 \pm 9.2$ & $104.5 \pm 12.7$ & $98.3 \pm 10.8$ & $102.6 \pm 2.3$ & $100.7 \pm 7.9$ & $108.0 \pm 3.0$ & $90.9 \pm 10.7$ \\
\hline
\end{tabular}

TABLE 3: Permeation of compounds through Caco-2 cell monolayers in $6 \mathrm{~h}$ incubation period, as percentage of compound found in the basolateral and intracellular compartments and as permeation rate $\left(\mathrm{mAU} \cdot \mathrm{mL} \cdot \mathrm{cm}^{-2}\right)$.

\begin{tabular}{|c|c|c|c|c|c|c|}
\hline \multirow{3}{*}{ Compound } & \multicolumn{4}{|c|}{ Permeation in $\%$ of the initial amount } & \multirow{2}{*}{\multicolumn{2}{|c|}{$\begin{array}{l}\text { Permeation rate } \\
\left(\mathrm{mAU} \cdot \mathrm{mL} \cdot \mathrm{cm}^{-2}\right)\end{array}$}} \\
\hline & \multicolumn{2}{|c|}{ Basolateral compartment } & \multicolumn{2}{|c|}{ Intracellular compartment } & & \\
\hline & Decoction & Infusion & Decoction & Infusion & Decoction & Infusion \\
\hline 1 & $38.5 \pm 6.6$ & $17.2 \pm 0.3$ & $21.4 \pm 0.4$ & $10.0 \pm 0.5$ & $1.68 \pm 0.29$ & $2.15 \pm 0.03$ \\
\hline 2 & $46.2 \pm 4.5$ & $43.5 \pm 4.3$ & $18.8 \pm 2.4$ & $15.8 \pm 2.1$ & $3.15 \pm 0.50$ & $3.49 \pm 0.22$ \\
\hline 3 & $19.2 \pm 1.0$ & $37.2 \pm 2.2$ & $9.6 \pm 0.4$ & $14.4 \pm 0.5$ & $1.59 \pm 0.13$ & $2.00 \pm 0.12$ \\
\hline 4 & $13.0 \pm 2.7$ & $22.9 \pm 3.9$ & $5.6 \pm 3.1$ & $9.6 \pm 0.8$ & $1.82 \pm 0.37$ & $2.14 \pm 0.38$ \\
\hline 5 & $10.2 \pm 3.5$ & $2.2 \pm 1.0$ & $5.7 \pm 0.8$ & $2.1 \pm 0.2$ & $1.07 \pm 0.43$ & $0.81 \pm 0.37$ \\
\hline 6 & $34.5 \pm 2.4$ & $31.4 \pm 1.1$ & $17.8 \pm 0.9$ & $10.1 \pm 0.1$ & $2.58 \pm 0.30$ & $5.51 \pm 0.21$ \\
\hline 7 & $47.6 \pm 0.6$ & $44.5 \pm 0.6$ & $31.0 \pm 0.6$ & $29.2 \pm 0.8$ & $48.70 \pm 0.38$ & $48.43 \pm 1.07$ \\
\hline
\end{tabular}

statistically significant. The results shown here point out that after a simulated digestive process the activity of the infusion or decoction is not reduced by the gastric or pancreatic juices and can be used for further studies, because it can pass through the gastrointestinal upper tract without any detectable modification. Our results are in accordance with those reported for Lavandula viridis extracts [45], whose overall antioxidant and anticholinesterase activities were assured after in vitro gastrointestinal digestion.

3.4. Bioavailability of the Components. According to the in vitro digestive process adopted in this work, the bioactive components of the E. australis aqueous extracts are not hydrolysed in the gastrointestinal tract conditions. However, the health improving effects of the aqueous extracts are only effective if the active compounds are able to permeate intestinal barrier to the blood stream. If the compounds can circulate in the blood stream, they may be able to reach the organs where they may be needed as radical scavengers, to decrease inflammation, or to the brain, where they may inhibit acetylcholinesterase activity and can be useful in the symptomatic treatment of Alzheimer's disease.

For each of the main compounds of E. australis extracts, the percentage of the initial amount that permeated through the basolateral compartment after 6 hours of incubation with the whole extracts was calculated (Table 3 ).

The cells were then lysed and the percentage of the compound to be found inside the cells (referred to as intracellular compartment) was calculated. As can be seen in Table 3, all the compounds were able to permeate through the cell membranes to the intracellular and basolateral compartments. Generally, the permeation was similar for the compounds found in the infusion and decoction; however, compounds 1 and 5 showed higher percentage of permeation in the decoction, and compounds $\mathbf{3}$ and $\mathbf{4}$ showed higher percentage of permeation in the infusion. These differences may be due to a higher initial amount of compounds 1 and $\mathbf{5}$ in the infusion and $\mathbf{3}$ and $\mathbf{4}$ in the decoction, as shown in the HPLC chromatograms (Figure 1), which may cause the saturation of the transporters for these compounds. This fact is also supported by the permeation rate values for these constituents (Table 3 ), which show very small differences between the infusion and decoction.

Compound 7 showed a permeation rate significantly higher than all the other compounds in the aqueous extracts. This suggests that its lower polarity may confer it higher lipophilicity, and therefore it may be able to permeate through the membranes independent of transporters. RodríguezRoque and coworkers [46] referred to the high bioaccessibility of quercetin and showed that the food matrix exerted a significant influence on the bioaccessibility of different bioactive molecules. An extensive review concerning flavonoid bioavailability and attempts for bioavailability enhancement was recently reported [47], showing that factors like molecular weight, glycosylation, metabolic conversion, and interaction with colonic microflora significantly affect flavonoids' bioavailability.

\section{Conclusions}

The present work evidences that in vitro gastrointestinal studies are useful tools to predict the chemical stability, bioactivity, and bioavailability of compounds present in medicinal 
plant extracts, giving a scientific support to their ethnopharmacological applications. After a simulated digestive process, no significant alterations in the chemical composition or in the antioxidant and anticholinesterase activities of E. australis extracts were observed. Moreover, the extracts' components were able to permeate through Caco-2 cell monolayers, denoting their bioavailability. Our work shows scientific evidence to support the potential of this plant as a source of functional ingredients and bioactive molecules for the prevention and treatment of neurodegenerative diseases and other free-radical related ailments.

\section{Conflict of Interests}

The authors declare that there is no conflict of interests regarding the publication of this paper.

\section{Acknowledgments}

This work was supported by Fundação para a Ciência e a Tecnologia (Project PEst-OE/QUI/UI0612/2013). The authors also thank the European Commission for the approval of the INOVAFUNAGEING commitment and the support of the project "PERsonalised ICT Supported Service for Independent Living and Active Ageing," FP7-ICT-2013-10, Project no. 610359, 2013-2016. The authors gratefully acknowledge Eng. Joaquim Morgado and Dr. John McAdam from Ervital, for supplying plant material.

\section{References}

[1] A. B. Sassi, F. Harzallah-Skhiri, N. Bourgougnon, and M. Aouni, "Antiviral activity of some Tunisian medicinal plants against Herpes simplex virus type 1," Natural Product Research, vol. 22, no. 1, pp. 53-65, 2008.

[2] C. Sadki, B. Hacht, A. Souliman, and F. Atmani, "Acute diuretic activity of aqueous Erica multiflora flowers and Cynodon dactylon rhizomes extracts in rats," Journal of Ethnopharmacology, vol. 128, no. 2, pp. 352-356, 2010.

[3] E. K. Akkol, E. Yeşilada, and A. Güvenç, "Valuation of antiinflammatory and antinociceptive activities of Erica species native to Turkey," Journal of Ethnopharmacology, vol. 116, no. 2, pp. 251-257, 2008.

[4] Â. Luís, F. Domingues, and A. P. Duarte, "Bioactive compounds, RP-HPLC analysis of phenolics, and antioxidant activity of some Portuguese shrub species extracts," Natural Product Communications, vol. 6, no. 12, pp. 1863-1872, 2011.

[5] R. D. Pavlović, B. Lakušić, Z. Došlov-Kokoruš, and N. Kovačević, "Arbutin content and antioxidant activity of some Ericaceae species," Pharmazie, vol. 64, no. 10, pp. 656-659, 2009.

[6] M. Reyes, C. Martin, C. A. de la Lastra, J. Trujillo, and M. V. Toro, "Antiulcerogenicity of the flavonoid fraction from Erica andevalensis Cabezudo-Rivera," Zeitschrift für Naturforschung C: Journal of Biosciences, vol. 51, no. 7-8, pp. 563-569, 1996.

[7] M. Reyes Ruiz, C. Martín-Cordero, M. J. Ayuso González, M. V. Toro Sainz, and C. Alarcón De La Lastra, "Antiulcer activity in rats by flavonoids of Erica andevalensis Cabezudo-Rivera," Phytotherapy Research, vol. 10, no. 4, pp. 300-303, 1996.
[8] Ö. Ertürk, "Antibacterial and antifungal activity of ethanolic extracts from eleven spice plants," Biologia, vol. 61, no. 3, pp. 275-278, 2006.

[9] H. Harnafi, N. E. H. Bouanani, M. Aziz, H. Serghini Caid, N. Ghalim, and S. Amrani, "The hypolipidaemic activity of aqueous Erica multiflora flowers extract in Triton WR-1339 induced hyperlipidaemic rats: a comparison with fenofibrate," Journal of Ethnopharmacology, vol. 109, no. 1, pp. 156-160, 2007.

[10] A. M. Nayebi, H. Nazemiyeh, R. Omidbakhsh, and S. Çobanoglu, "Analgesic effect of the methanol extract of Erica arborea (L.) in mice using formalin test," Daru, vol. 16, no. 4, pp. 229-232, 2008.

[11] C. Martín-Cordero, M. Reyes, M. J. Ayuso, and M. V. Toro, "Cytotoxic triterpenoids from Erica andevalensis," Zeitschrift für Naturforschung C: Journal of Biosciences, vol. 56, no. 1-2, pp. 4548, 2001.

[12] J. M. Neves, C. Matos, C. Moutinho, G. Queiroz, and L. R. Gomes, "Ethnopharmacological notes about ancient uses of medicinal plants in Trás-os-Montes (northern of Portugal)," Journal of Ethnopharmacology, vol. 124, no. 2, pp. 270-283, 2009.

[13] R. Nunes, A. Anastácio, and I. S. Carvalho, "Antioxidant and free radical scavenging activities of different plant parts from two Erica Species," Journal of Food Quality, vol. 35, no. 5, pp. 307-314, 2012.

[14] R. Nunes and I. S. Carvalho, "Antioxidant activities, distribution of phenolics and free amino acids of Erica australis L. leaves and flowers collected in Algarve, Portugal," Natural Product Research, vol. 27, no. 18, pp. 1664-1667, 2013.

[15] R. Nunes, S. Rodrigues, P. Pasko, M. Tyszka-Czochara, A. Grenha, and I. S. De Carvalho, "Effect of Erica australis extract on Caco-2 cells, fibroblasts and selected pathogenic bacteria responsible for wound infection," Industrial Crops and Products, vol. 52, pp. 99-104, 2014.

[16] A. Carballeira, "Phenolic inhibitors in Erica australis L. and in associated soil," Journal of Chemical Ecology, vol. 6, no. 3, pp. 593-596, 1980.

[17] M. V. T. Sainz, M. D. G. Gimenez, and M. P. Martinez, "Isolation and identification of phenol acids from Erica andevalensis Cabezudo-Ribera: their contribution to an antibacterial activity," Annales Pharmaceutiques Francaises, vol. 45, no. 5, pp. 401407, 1987.

[18] M. D. A. Rubio, M. J. A. Gonzalez, M. D. G. Gimenez, and M. V. T. Sainz, "Flavonols isolated from Erica-andevalensis Cabezudo-Ribera contribution to the study of the antimicrobial activity of the species," Plantes Medicinales et Phytotherapie, vol. 22, no. 2, pp. 113-118, 1988.

[19] B. Bennini, A. J. Chulia, M. Kaouadji, and F. Thomasson, "Flavonoid glycosides from Erica cinerea," Phytochemistry, vol. 31, no. 7, pp. 2483-2486, 1992.

[20] D. C. Gournelis, "Flavonoids of Erica verticillata," Journal of Natural Products, vol. 58, no. 7, pp. 1065-1069, 1995.

[21] B. Tepe, D. Daferera, A. Sokmen, M. Sokmen, and M. Polissiou, "Antimicrobial and antioxidant activities of the essential oil and various extracts of Salvia tomentosa Miller (Lamiaceae)," Food Chemistry, vol. 90, no. 3, pp. 333-340, 2005.

[22] K. Ingkaninan, P. Temkitthawon, K. Chuenchom, T. Yuyaem, and W. Thongnoi, "Screening for acetylcholinesterase inhibitory activity in plants used in Thai traditional rejuvenating and neurotonic remedies," Journal of Ethnopharmacology, vol. 89, no. 2-3, pp. 261-264, 2003.

[23] Y. Yamamoto, Y. Takahashi, M. Kawano et al., "In vitro digestibility and fermentability of levan and its hypocholesterolemic 
effects in rats," The Journal of Nutritional Biochemistry, vol. 10, no. 1, pp. 13-18, 1999.

[24] P. L. Falé, L. Ascensão, and M. L. M. Serralheiro, "Effect of luteolin and apigenin on rosmarinic acid bioavailability in Caco-2 cell monolayers," Food \& Function, vol. 4, no. 3, pp. 426431, 2013.

[25] Z. Qiang, Z. Ye, C. Hauck et al., "Permeability of rosmarinic acid in Prunella vulgaris and ursolic acid in Salvia officinalis extracts across Caco-2 cell monolayers," Journal of Ethnopharmacology, vol. 137, no. 3, pp. 1107-1112, 2011.

[26] H. Suzuki, R. Sasaki, Y. Ogata et al., "Metabolic profiling of flavonoids in Lotus japonicus using liquid chromatography Fourier transform ion cyclotron resonance mass spectrometry," Phytochemistry, vol. 69, no. 1, pp. 99-111, 2008.

[27] J. H. Lee, S. J. Lee, S. Park et al., "Characterisation of flavonoids in Orostachys japonicus A. Berger using HPLC-MS/MS: contribution to the overall antioxidant effect," Food Chemistry, vol. 124, no. 4, pp. 1627-1633, 2011.

[28] H. Yang, Y. Ge, Y. Sun, D. Liu, X. Ye, and D. Wu, "Identification and characterisation of low-molecular-weight phenolic compounds in bayberry (Myrica rubra Sieb. et Zucc.) leaves by HPLC-DAD and HPLC-UV-ESIMS," Food Chemistry, vol. 128, no. 4, pp. 1128-1135, 2011.

[29] L. L. Saldanha, W. Vilegas, and A. L. Dokkedal, "Characterization of flavonoids and phenolic acids in Myrcia bella cambess. Using FIA-ESI-IT-MSn and HPLC-PAD-ESI-IT-MS combined with NMR," Molecules, vol. 18, no. 7, pp. 8402-8416, 2013.

[30] N. H. N. Hashim, F. Abas, K. Shaari, and N. H. Lajis, "LCDAD-ESIMS/MS characterization of antioxidant and anticholinesterase constituents present in the active fraction from Persicaria hydropiper," LWT-Food Science and Technology, vol. 46, no. 2, pp. 468-476, 2012.

[31] S. I. Falcão, N. Vale, P. Gomes et al., "Phenolic profiling of portuguese propolis by LC-MS spectrometry: uncommon propolis rich in flavonoid glycosides," Phytochemical Analysis, vol. 24, no. 4, pp. 309-318, 2013.

[32] S. Ruslay, F. Abas, K. Shaari et al., "Characterization of the components present in the active fractions of health gingers (Curcuma xanthorrhiza and Zingiber zerumbet) by HPLCDAD-ESIMS," Food Chemistry, vol. 104, no. 3, pp. 1183-1191, 2007.

[33] C.-L. Hsu, S.-C. Fang, and G.-C. Yen, "Anti-inflammatory effects of phenolic compounds isolated from the flowers of Nymphaea mexicana Zucc.", Food \& Function, vol. 4, no. 8, pp. 1216-1222, 2013.

[34] T. Fossen, Å. Larsen, B. T. Kiremire, and Ø. M. Andersen, "Flavonoids from blue flowers of Nymphaea caerulea," Phytochemistry, vol. 51, no. 8, pp. 1133-1137, 1999.

[35] H. Nazemiyeh, F. Bahadori, A. Delazar et al., "Antioxidant phenolic compounds from the leaves of Erica Arborea (Ericaceae)," Natural Product Research, vol. 22, no. 16, pp. 1385-1392, 2008.

[36] M. Ay, F. Bahadori, M. Öztürk, U. Kolak, and G. Topçu, "Antioxidant activity of Erica arborea," Fitoterapia, vol. 78, no. 7-8, pp. 571-573, 2007.

[37] S.-S. Huang, G.-J. Huang, Y.-L. Ho et al., "Antioxidant and antiproliferative activities of the four Hydrocotyle species from Taiwan," Botanical Studies, vol. 49, no. 4, pp. 311-322, 2008.

[38] E. A. Adewusi, N. Moodley, and V. Steenkamp, "Medicinal plants with cholinesterase inhibitory activity: a review," African Journal of Biotechnology, vol. 9, no. 49, pp. 8257-8276, 2010.
[39] S. Sasho, H. Obase, S. Ichikawa et al., "Synthesis of 2imidazolidinylidene propanedinitrile derivatives as stimulators of gastrointestinal motility-III," Bioorganic \& Medicinal Chemistry, vol. 3, no. 3, pp. 279-287, 1995.

[40] P. L. Falé, F. Amaral, P. J. A. Madeira et al., "Acetylcholinesterase inhibition, antioxidant activity and toxicity of Peumus boldus water extracts on HeLa and Caco-2 cell lines," Food and Chemical Toxicology, vol. 50, no. 8, pp. 2656-2662, 2012.

[41] M. F. Hernandez, P. L. V. Falé, M. E. M. Araújo, and M. L. M. Serralheiro, "Acetylcholinesterase inhibition and antioxidant activity of the water extracts of several Hypericum species," Food Chemistry, vol. 120, no. 4, pp. 1076-1082, 2010.

[42] A. T. Mata, C. Proença, A. R. Ferreira, M. L. M. Serralheiro, J. M. F. Nogueira, and M. E. M. Araújo, "Antioxidant and antiacetylcholinesterase activities of five plants used as Portuguese food spices," Food Chemistry, vol. 103, no. 3, pp. 778-786, 2007.

[43] X. Ding, M.-A. Ouyang, X. Liu, and R.-Z. Wang, "Acetylcholinesterase inhibitory activities of flavonoids from the leaves of Ginkgo biloba against brown planthopper," Journal of Chemistry, vol. 2013, Article ID 645086, 4 pages, 2013.

[44] L. Siracusa, T. Kulisic-Bilusic, O. Politeo, I. Krause, B. Dejanovic, and G. Ruberto, "Phenolic composition and antioxidant activity of aqueous infusions from Capparis spinosa L. and Crithmum maritimum $\mathrm{L}$. before and after submission to a two-step in vitro digestion model," Journal of Agricultural and Food Chemistry, vol. 59, no. 23, pp. 12453-12459, 2011.

[45] P. Costa, T. Grevenstuk, A. M. Rosa da Costa, S. Gonçalves, and A. Romano, "Antioxidant and anti-cholinesterase activities of Lavandula viridis L'Hér extracts after in vitro gastrointestinal digestion," Industrial Crops and Products, vol. 55, pp. 83-89, 2014.

[46] M. J. Rodríguez-Roque, M. A. Rojas-Graü, P. Elez-Martínez, and O. Martín-Belloso, "In vitro bioaccessibility of healthrelated compounds from a blended fruit juice-soymilk beverage: influence of the food matrix," Journal of Functional Foods, vol. 7, no. 1, pp. 161-169, 2014.

[47] S. H. Thilakarathna and H. P. Vasantha Rupasinghe, "Flavonoid bioavailability and attempts for bioavailability enhancement," Nutrients, vol. 5, no. 9, pp. 3367-3387, 2013. 


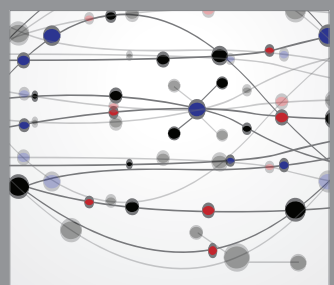

The Scientific World Journal
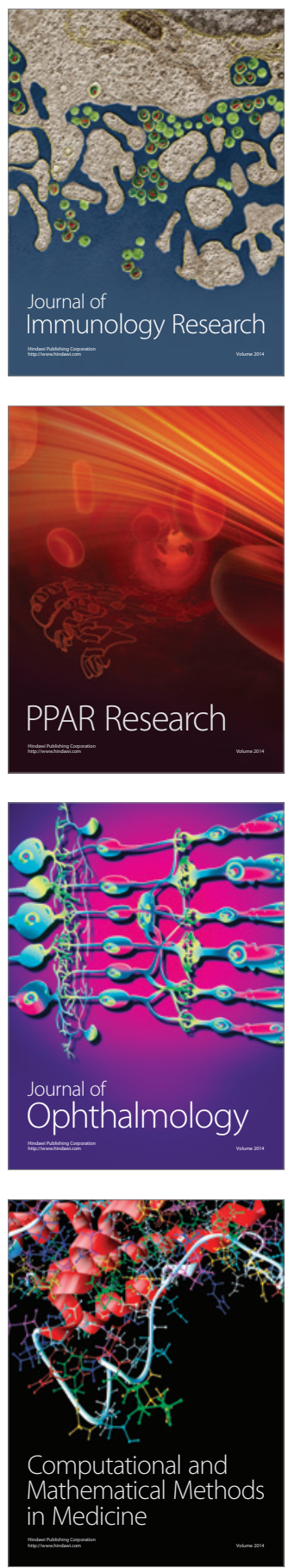

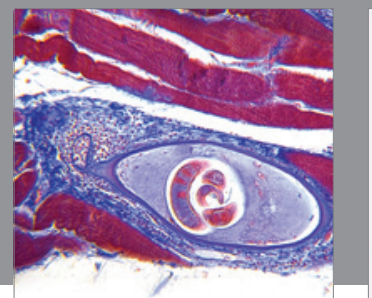

Gastroenterology

Research and Practice
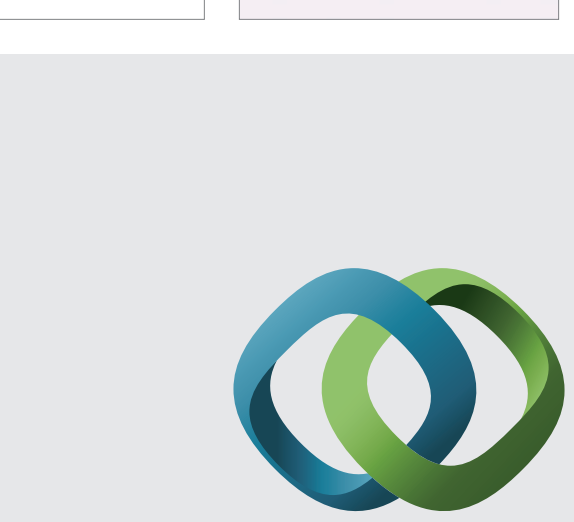

\section{Hindawi}

Submit your manuscripts at

http://www.hindawi.com
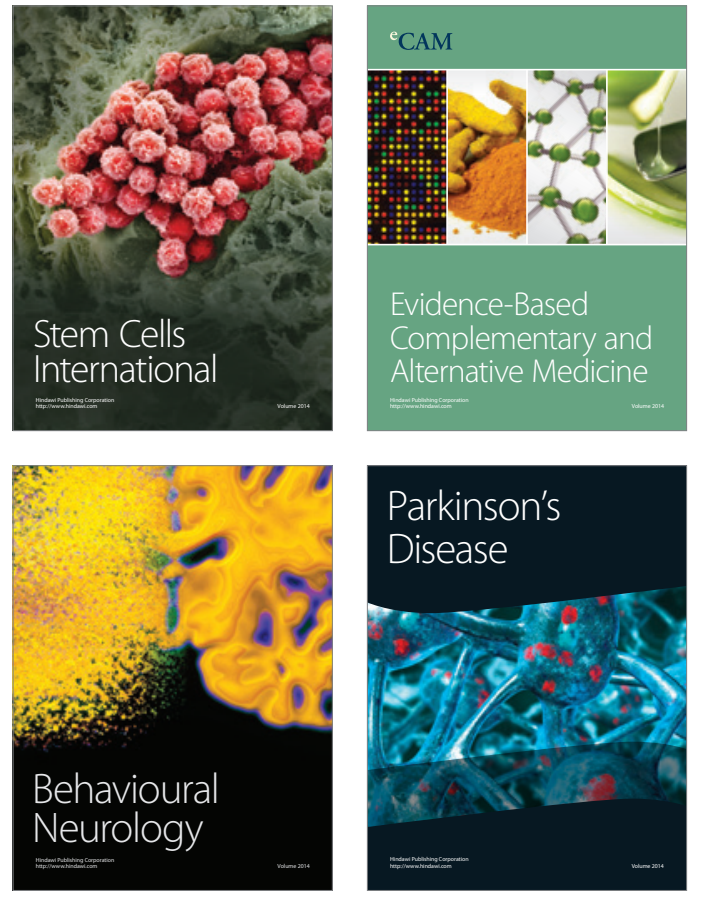
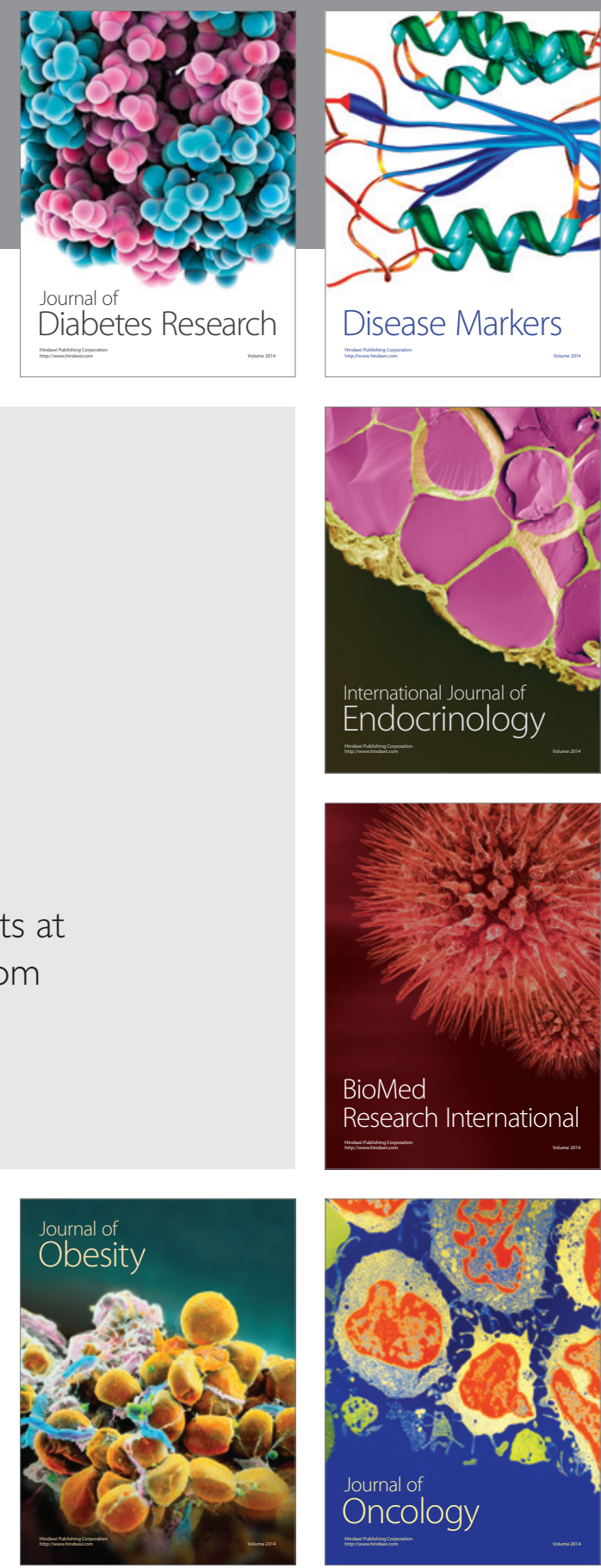

Disease Markers
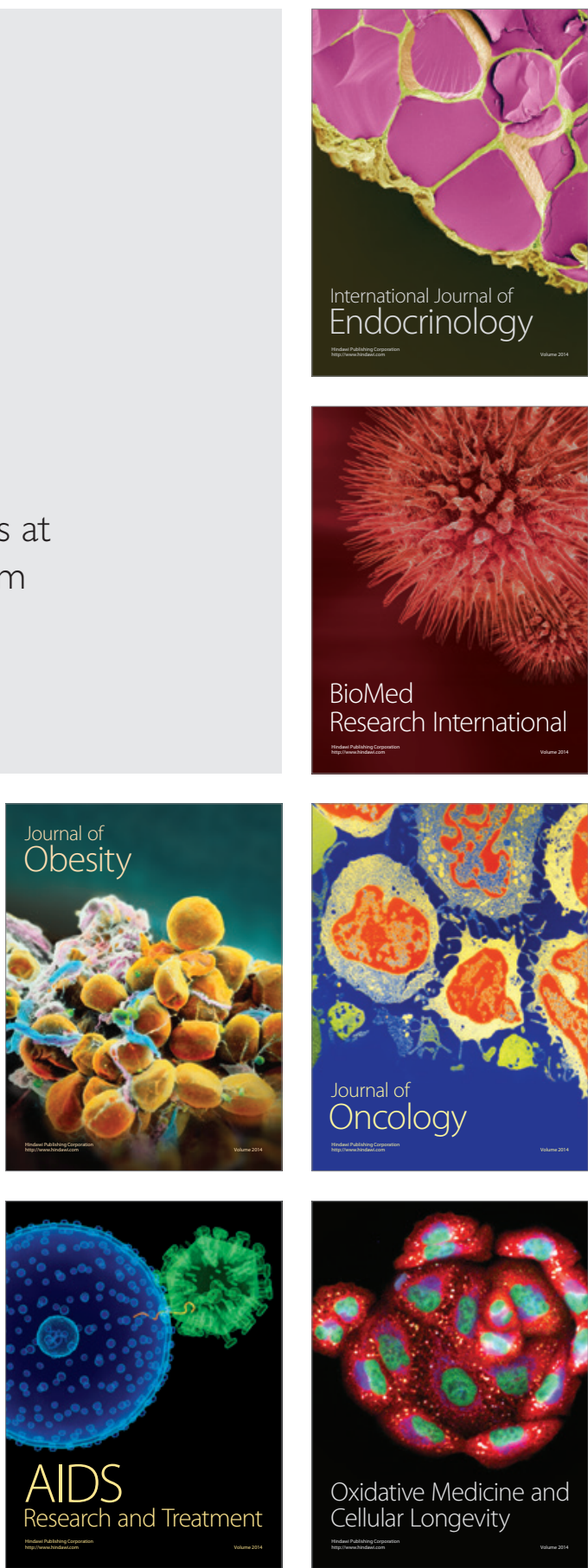